\title{
Building Models of Adult Second-Language Writing Instruction
}

\author{
Alister Cumming, Ontario Institute for Studies in Education, Canada
}

Abdolmehdi Riazi, Shiraz University, Iran

Paper presented July 12, 1996 at the Seminar, Second Language Acquisition and Writing: A

Multi-Disciplinary Approach, University of Southampton.

Address correspondence to: Alister Cumming, Modern Language Centre,

Ontario Institute for Studies in Education, 252 Bloor Street West, Toronto, Ontario, Canada M5S

1V6; Internet: acumming@oise.on.ca

Phone: 1-416-923-6641, ext. 2538 Fax: 1-416-926-4725

We thank the Social Sciences and Humanities Research Council of Canada (standard grant 41091-0722) for supporting the research reported in this paper; Sue Elgie for advice on analyses; as well as Michael Lessard-Clouston, Jiang Li, Susanna Lo, Kara Moscoe, Hiroko Saito, Ling Shi and Sufumi So for assistance in data collection. Certain findings from this research were reported in October, 1994 under the title "Learning variables and achievement in ESL written composition" at the Second Language Research Forum, Montreal. 


\section{Building Models of Adult Second-Language Writing Instruction}

Abstract: This paper first reviews recent attempts to describe formal models of second-language writing; we then identify three major issues in need of clarification to advance model-building in this domain. We discuss these issues in respect to findings from a preliminary attempt to develop a process-product model of ESL writing instruction based on analyses of antecedent, process and outcome variables for 108 ESL learners from diverse cultural backgrounds in 6-week intensive courses at a Canadian university. Findings from multivariate, regression, correlation and exploratory factor analyses indicated the tentative model had little explanatory power overall but pointed toward interesting interactions in achievement for (a) different aspects of L2 writing among (b) learners at different levels of L2 proficiency and with (c) differing orientations to learning L2 writing. 
As research on writing in second languages has proliferated over the past two decades, so have the conceptualizations that people have offered of what writing in a second language is, how people learn to do it, and how it should be taught. The purposes of this paper are first to review the empirical models that have arisen from some of these conceptualizations, particularly those that have made serious claims for theoretical status and empirical validity in reference to education. Then we describe three major issues in need of preliminary clarification before more extensive, relevant models can be constructed. We discuss these issues in respect to certain decisions and findings from a recent project in which we tried to move model-building forward in directions that we believe further research needs to pursue if we are to understand secondlanguage writing more comprehensively and in a way that can systematically inform educational practices and further inquiry.

We use the term "models" to describe those conceptualizations that have been articulated formally, suitable for critical scrutiny and validation. Such models are increasingly important as concerns for educational standards and "best practices" become commonplace, shaping the goals and frameworks of learning and teaching, for example, through outcomes-oriented curricula and system-wide testing. We focus primarily on adults writing in English as a Second Language (ESL), reflecting the international spread of this language and the significance of literacy in it. Our focus on adults aims to avoids confusion with the many maturational variables associated with children's initial development of literacy and schooling, but this focus also opens up numerous other, complicated issues intimately related to writing in a second language, such as the varied substantive knowledge, prior literate skills, situations of language contact, or diverse life experiences that adults may or may not possess when they learn to write in a second 
language.

An initial observation about models of second-language writing are that there are really not very many of them. Moreover, very few are framed in terms that aim to account comprehensively for the complexities of educational circumstances. As Raimes (1991) and Silva (1990) have observed, there have been many conceptualizations of (a) texts written in second languages, (b) students' writing processes and characteristics, (c) ways of evaluating secondlanguage writing, and (d) the social contexts in which second-language writing or learning occurs. But there are scarcely any models that have attempted to link these fundamental elements together formally or coherently, apart from certain teaching methods expressed as guidance for instruction, rather than full-scale educational models. Indeed, our sense is that the only formal model of second-language writing that has influenced education broadly over the past two decades is the extremely general one proposed by Carroll (1975) in his model of skill learning. Carroll's model set writing out as one of four comprehensive skills in a second language (along with reading, listening and speaking), but the model had little more to say specifically about the nature of second-language writing, other than that it could be tested reliably with short composition tasks. Cummins' interdepedence hypothesis (e.g., Cummins, 1991) has been widely cited in recent years, but mainly just to confirm that basic aspects of literacy developed in the mother-tongue do transfer to literacy tasks in a second language. This lack of serious model-building in respect to second-language writing contrasts with the extensive theoretically-oriented inquiry focused on oral aspects of second-language proficiency and spoken discourse in classroom contexts (cf. Chaudron, 1988; Ellis, 1994; Harley, Allen \& Swain, 1990). 
Although considerable experimental research, such as Cumming (1989, 1990b), Whalen and Menard (1995) or Zimmerman (this volume), has recently refined our descriptions of the psycholinguistic processes of composing in second languages, the experimental basis of such studies has limited their relevance and scope in comparison to research that is situated firmly in natural education contexts. Indeed, a severe criticism that can be made of a majority of research on writing in second languages is that it has utilized isolated composing tasks whose validity or representativeness is limited to the performance of these tasks alone, being separated artificially (like most experimentation) from the usual complexities of learning and teaching. As a consequence, considerable information now exists describing how people compose in a second language and the features of the texts they produce for single writing tasks, but we have very little information on how people actually learn to write in second languages or how teaching might influence this. This is an unseemingly position to be in for inquiry that makes implications for education its major justification and claim to relevance. For this reason, research within educational programs is necessary not only to account realistically for what occurs in learning and teaching practices but also to help to explain them.

\section{Recent Approaches to Model-Building in Educational Contexts}

What analytic approaches have been attempted to date? What information do they provide for building models of second-language writing instruction? Four analytic techniques have reported notable (albeit preliminary) success in developing and evaluating models of second-language writing that are relatively comprehensive and grounded in empirical data from natural educational contexts: meta-analysis, cross-sectional studies, longitudinal studies, and explanatory modeling. 
Silva's (1993) meta-analysis of 72 empirical studies that had compared people's writing in first and second languages identified a consistent set of findings that distinguish the two modes of writing, presenting a firm case for the distinct nature of second-language writing in terms of unique composing processes and unique features of written texts, differing from those observed in writing in the mother tongue. Assuming a much broader perspective on biliteracy, Hornberger (1989, and see applications in Cumming, 1994) synthesized studies of language policy and research on reading and writing in second languages to delineate a range of nine continua, on the basis of which situations for developing biliteracy vary in fundamental ways internationally, such as learners' extent and sequence of contact with literacy in a second language, social norms for bilingualism or monolingualism, or the convergence or divergence of scripts or of oral and literate modes of communication. Whereas Silva used meta-analytic techniques to identify, from existing research, certain discrete elements that are common to people's writing behavior in second languages, Hornberger outlined broadly what the conditions for developing secondlanguage literacy are, showing that far from representing a single type of situation, these vary substantively in distinctive ways--sociolinguistically, psycholinguistically and in reference to educational contexts.

Cross-sectional research designs have studied second-language writing among groups of similar learners at different points in the same educational programs. For example, Tarone et al. (1993) compared groups of Southeast Asian-American students in ESL classes at grades 8, 10, and 12 in secondary schools and at a university in Minneapolis, finding a disturbing lack of longterm development across these age spans for the one population, then inferring that these students require considerably more support for their literacy development during high school. 
Similarly, Bardovi-Harlig and Bofman (1989) analyzed texts written by groups of ESL students at an American university who had either met or not met the minimum level on the TOEFL (Test of English as a Foreign Language) required for admisssion to the university, finding their syntactic expression comparable but that the groups differed markedly in their command of English morphology, suggesting this aspect of English is an obvious area on which to focus teaching.

These examples of cross-sectional research begin to reveal certain interrelations between the learning and teaching of second-language writing. By virtue of their situation in real educational settings, they speak directly to educators' concerns for curriculum or instructional policies, and they account for these as they may occur. But in view of building models, this approach to research has certain limitations. It is virtually impossible to tell if the groups that cross-sectional inquiries might compare are truly equivalent or if the students (or their learning or teaching) might have been influenced by subtle variables beyond the scope of the research. In terms of model-building or hypothesis-testing, the evidence that cross-sectional designs offer is never sufficient for explanatory purposes. Similarly, in terms of educational relevance, this approach to research makes it difficult to avoid a deficit model of learning, i.e., one that faults the baseline learners for what they lack--suggesting that their deficiencies should form the basis for instruction, but without knowing if instruction addressing such lacks would really be effective.

Longitudinal studies and path analyses are two analytic techniques that do offer explanatory potential and a firm basis for model-building relevant to education. A recent example of longitudinal research is Kern and Schultz's (1992) study of the achievement in 
writing made by 415 American students of French during the progress of one university course, describing trends in scores from holistic ratings and syntactic analyses of their writing in French at four intervals over eight months. Such documentation--tracing the development that students actually make in their second-language writing--is vital to demonstrate how learning to write in a second-language happens, although the explanatory potential of this particular study was limited by the gross measures it used (and thus it was not able to describe the texts students produced in a very informative way) and a lack of information on the learners, their learning, or the teaching processes involved, such as could have accounted for the development in writing they displayed. (See Weissburg's study in the present volume for another example of longitudinal research.)

A notable effort to account systematically for some of these factors appears in Sasaki and Hirose's (1996) and Hirose and Sasaki's (1994) studies of writing by adult Japanese learners of English. Aiming to evaluate the major factors related to variation in these learners' secondlanguage writing, Sasaki and Hirose devised measures to assess students' backgrounds and attititudes, proficiency in the second language, literacy in their mother tongue, and strategies for composing, then analyzed scores from these measures in relation to the students' writing performance in English and in Japanese, developing a hypothetical path analysis to describe how these key factors interrelated empirically. In aspiring to evaluate comprehensively a set of educationally-relevant factors that may influence the effectiveness of students' writing in a second language, Sasaki and Hirose make a major step forward in model-building in this domain, although their research still lacks confirmation from studies in other settings and longitudinal data such as could verify their hypothetical model. 
In particular, their studies point the way toward the kind of model that might account systematically for (a) the presage or antecedent variables in learners' backgrounds and an educational context along with (b) the long-term processes of learning and teaching that could explain (c) the achievements that students make in second-language writing. These elements of process-product models are now conventional in educational research (e.g., Gage \& Needels, 1989) and in discussions of oral aspects of second-language learning in classroom contexts (e.g., Chaudron, 1988; Stern, 1983). But, as we try to demonstrate in the remainder of this paper, similar models are needed for second-language writing, despite the difficulty of ascertaining them due to the very complexity of this educational phenomenon.

\section{Building Models of Second-Language Writing Instruction: Three Key Issues and Examples from a Preliminary Attempt}

The studies reviewed above highlight three major issues in need of clarification for the purposes of building models of second-language writing relevant to education:

1. What are appropriate indicators of achievement in second-language writing?

2. What are the principal variables that influence learning to write in a second language in an educational context? What data should be gathered to describe them?

3. How do these variables interrelate (as processes of learning) to produce students' achievement in second-language writing?

We consider these issues in reference to a study we recently conducted in colloboration with several graduate students, citing decisions we made in the process of this research as well as selected findings from it. Our study was a preliminary attempt to develop a process-product model of second-language writing, based empirically on the natural situation of teaching and 
learning in one intensive ESL program. We tried to develop a model, in a bottom-up fashion, rather than to test one we had devised a priori. The study spanned an initial year of observations in classrooms and interviews with students and teachers, a second year of pilot trials and refinement of instruments, and a third year of data collection and analyses. The study was situated in the context of an intensive ESL program at a large Canadian university, where young adult students typically spend one or two semesters learning English either in preparation for further academic studies in Canada or as a short-term experience abroad. During the period of the research, the student population consisted of young to middle-aged adults with diverse language, cultural and educational backgrounds but distinct numbers from Hong Kong, Japan, Tawain, and Latin America. We worked with five experienced ESL instructors (described in Shi $\&$ Cumming, 1995) over the duration of the study, documenting their classes on a weekly basis and collecting data from their rotating groups of students (with intermediate to advanced levels of English proficiency) at the beginnings and ends of six-week terms of instruction during the academic years of 1991-92, 1992-93 and 1993-94. The findings we report below derive from data for 108 students collected in four separate classes taught by four teachers over two terms of the program; however, because of attrition, missing data, and incomplete sets of matching data many analyses could only be conducted for 73 of these people.

\section{Indicators of Achievement in Second Language Writing}

Developing a model that tries to explain second-language writing requires a precise definition of the construct. To determine what people might learn in respect to second-language writing we have to know what changes in their writing performance are significant and valid indicators of learning (Cumming \& Mellow, 1996). This is a complex issue because virtually all 
existing tests of second-language writing aim to group or sort learners for the purposes of placement or admissions into educational programs, not for achievement testing (Cumming, in press). If based on raters' holistic impressions of students' texts, as most of these instruments are, they are simply not fine-grained enough to evaluate precise, longitudinal changes in students' writing, a point that was evident in our pilot attempts to use instruments like Jacobs et al.'s (1981) Composition Profile in our study. Although some research has started to identify the "objective" characteristics of ESL students' written texts that correspond to levels of proficiency in second-language writing, there is no consensus on the indicators that one could validly use to do so, and the range of these proposed to date is enormous (for reviews, see Cumming \& Mellow, 1996; Cumming, in press).

Moreover, there is considerable controversy over the types of writing that need to be sampled to represent the construct of second-language writing. Although gathering single, brief compositions from students has been the predominant practice in language testing since at least Carroll (1975), most evidence suggests these alone are inadequate representations of the domain of second-language writing (e.g., Hamp-Lyons, 1991; Raimes, 1990) and thus inadequate for research purposes. Likewise, the practice of scoring compositions holistically (e.g., as in Kern \& Schultz, 1992) conflates the details of students' writing into a single score, obscuring the very elements that research into learning should be illuminating. Need one therefore look broadly into learners' routine uses of literacy in their daily lives, as in Cumming and Gill's (1991) yearlong study of several immigrant women learning to write in English in Canada? Or are brief compositions adequate indicators that students can compose coherent, meaningful written discourse in their second language? 
We opted in our research to utilize the analytic rating scheme developed and validated by Hamp-Lyons and Henning (1991), which defines multiple traits of second language writing-Communicative Quality, Organization, Argumentation, Language Accuracy, and Language Appropriacy--in 9-point scales. To implement our analyses we established inter-rater reliability coefficients above .96 among two raters for each of these scales with sample compositions from pilot studies then assessed pre- and post-term writing samples blindly as to whom they had been written by. The virtue of this rating scheme for research purposes is that it accounts for the multi-faceted nature of second-language writing, permitting analyses that can determine on which of these traits students' achievement may appear, anticipating variable achievement among learners in respect to different aspects of second-language writing (cf. Cumming, 1989, 1990a; Valdez, Haro \& Echevarriarza, 1992). We also opted, though with some reservations, to sample short compositions from students at the beginnings and ends of their terms of study, using a problem-solution composing task: "Describe a problem or situation where people often need help to learn English. Give reasons for your choice. Suggest one or more solutions to the problem." We administered this task in half-hour durations to students at the beginning and end of their terms of ESL study. In so doing we followed the rationale that this task represented the kind of testing that was usually done in this educational program and thus formed a relevant indication of second-language writing proficiency. Like Purves (1992), however, we still puzzle over the adequacy of this approach and its construct validity.

\section{Relevant Variables}

A second major issue in developing models of second-language writing instruction involves determining which variables to gather data on, which instruments to use to do this, and 
how to reduce the resulting data into empirical forms suitable for analyses. As noted above, process-product models conventionally distinguish (a) antecedent (or presage) variables related to students' personal characteristics and backgrounds prior to beginning an educational program and (b) process variables, including indicators for any processes that might reasonably bear an influence on students' achievement. In the case of our study, the identification of antecedent variables was relatively straightforward, as we adapted survey instruments validated in previous research (e.g., from Cumming, 1989; Cumming \& Gill, 1991) to gather information on students' gender, ages, mother tongues, occupational experiences writing, writing skills in their mother tongues, prior experiences learning English in their native countries, motivation for studying English, and so forth. Working in just one educational setting, we didn't attend to describing the overall institutional or societal context; but as a consequence, our research lacks documentation on the institutional norms and values that may have broadly influenced students' achievement (cf. Zamel, 1995), and we cannot we make any claims about external validity of this research or even say distinctly how the one context might relate to other ones like it.

Defining process variables was a truly exploratory venture, indeed a step into territories uncharted by any previous inquiry. So we worked from issues addressed in previous research as well as our initial year of observing classroom learning and teaching and of interviewing the people in this setting. To describe students' processes of learning, we synthesized our initial investigations and reviews of previous research on writing strategies into a survey instrument that asked students about their practices writing in English in classes and at home as well as the strategies they used for studying. We refined and verified this through in-depth interviews with a randomly-selected sample of 7 students using their mother tongues (Cantonese, Japanese, Farsi, 
and Mandarin) 2 weeks after they had completed the written questionnaires in English.

Similarly, we used preliminary findings from our interviews with students as well as syntheses of earlier studies to develop an instrument (described in detail in Saito, 1994) that asked learners about their preferences for feedback on their writing as well as their routine uses of such feedback from their teachers as well as their peers.

We also worked from Cumming's (1992) description of ESL teaching routines to develop an observation instrument that documented the behavior of the teachers in relevant terms, such as "assigning tasks", "modelling writing or language paradigms", "guiding individual development", or "providing feedback". We established inter-coder agreement on this instrument in pilot studies then documented the teachers' classes at weekly intervals (as reported in Riazi, Lessard-Clouston \& Cumming, 1994). Also, we interviewed the teachers weekly about the classes they had previously taught and their beliefs about second-language writing (as reported in Shi \& Cumming, 1995).

These exploratory approaches to documenting process variables had several shortcomings in respect to our purpose of model-building. For the survey instruments (on students' writing and study practices and on their preferences and uses of feedback), we were not certain, until our final analyses (and perhaps not still), whether these focused precisely on the variables that were crucial to the students' achievement. Moreover, reducing the extensive data they produced into a form suitable for analyses required exploratory factor analyses (see below) to identify empirically coherent groupings among the many items on these instruments. A further constraint is that our surveys of students' uses of English focused only on their writing; we lacked data on their various other (mostly oral) interactions in their other ESL classes and 
outside of classes. A serious limitations to our purposes of model-building appeared with the data from classroom observations and teacher interviews. Both approaches produced information that we think adequately described, respectively, the major features of the classroom teaching we observed and these teachers' relevant beliefs, but the detailed, largely qualitative form of these data, from only four teachers, could not be reduced in such a way as to permit meaningful analyses in conjunction with the other data we collected. So we have reported results from these aspects of our study separately, as noted above.

\section{Interrelations between Variables and Achievement Scores}

The goal of this kind of model-building research is of course to evaluate whether trends in the antecedent and process variables relate significantly to the outcome variables, in this case, students' achievement in their second-language writing. Although the project we have been describing produced numerous interesting findings, it ultimately fell short of having very much explanatory power. That is, the antecedent and process variables did not explain very much of the variance in the outcome variables. Like many similar studies, it fell prey overall to what Cronbach (1975) called the "interactive complexity" common to scientific investigations of multi-faceted human behavior. The sheer number of variables investigated and the extent to which they interact with each other defies identification of simple, straightforward causal relationships. Complex model-building opens up a hall of mirrors. Rather than despairing over this dilemma, however, we would prefer to think that the distinct findings that did emerge from our research are valuable in their own respect, the numerous interactions between variables reflect the actual complexity of issues involved in learning and teaching second language writing, and the preliminary steps we have taken in this study will help to pave 
the way toward future models of second-language writing instruction.

\section{Multivariate Analyses}

Three sets of findings are worth discussing for their relevance to future model-building. The first involved multivariate analyses, which we used (a) to assess students' pre-post term achievement in the five traits of second-language writing then (b) related to the antecedent variables documented. MANOVAs comparing students's writing scores at the beginnings and ends of their six-week terms of ESL study showed statistically significant differences $(N=73)$ for all but one of the five traits of second-language writing: communicative quality $(F=4.12, p=$ $.04)$, organization $(F=7.18, p=.009)$, argumentation $(F=2.81, p=$ n.s. $)$, linguistic accuracy $(F$ $=9.05, p=.004)$, and linguistic appropriacy $(F=9.29, p=.003)$. That is, except for the trait of argumentation (which was not crucial in the writing tasks we administered), the students overall made discernible achievements in their writing in English over six weeks of intensive ESL studies. Our selection of indicators of second-language achievement appeared appropriate to our research purposes.

Further within-subject MANOVAs of these scores revealed one interesting interaction between the personal characteristics of these learners and the achievement they made on particular aspects of their writing. Students who rated themselves as having high levels of writing skills in their mother tongues tended to have made significant improvements in their linguistic accuracy $(F=7.55, p=.008, n=68)$ and linguistic appropriacy $(F=10.60, p=.002, n$ $=68$ ) but not the other three traits rated in the compositions. We interpret this finding to offer some tentative support for the finding of Cumming (1990b), related to Swain's idea of comprehensible output (Swain, 1995), that people with high levels of writing expertise in their 
mother tongue may have developed capacities that help them to learn the language while composing purposefully in it, for example, through word searches and mentally matching intended meanings with linguistic forms.

Perhaps equally interesting, however, is the fact that no other significant interactions appeared among these analyses relating learners' personal characteristics to their achievement-apart from one for gender $(n=71)$, with males making greater improvement than females in linguistic accuracy $(F=3.69, p=.05)$ and linguistic appropriacy $(F=3.70, p=.05)$, but this probably reflects the imbalance of males to females among those who had greater writing expertise and experience writing in their mother tongues, and thus we think reflects the same finding discussed already above. Seemingly, these students made relatively uniform improvements in their writing despite the diversity of their backgrounds, for example, without differences that could be attributable to their ages, occupational experiences, intentions for further academic studies, or mother tongues.

Likewise, no significant differences appeared in any within-subjects MANOVAs assessing achievement on the five traits of ESL writing across the classes taught by the four different teachers. Seemingly, the achievement that the students made was equivalent irrespective of the teachers with whom they had studied, teachers whom we observed to have taught in fundamentally similar ways (Riazi, Lessard-Clouston \& Cumming, 1994) but to have had quite different individual beliefs about how second-language writing should be taught (Shi \& Cumming, 1995). 


\section{Exploratory Factor Analyses}

For a second approach to analyses we used exploratory factor analyses to identify trends in four logically grouped sets of the antecedent and process variables. Although of value only for descriptive rather than explanatory purposes, these analyses produced interesting profiles of the previous and current learning experiences of these students in respect to second-language writing. Using Principal Axis Factoring and OBLIMIN rotations until satisfactory factor solutions were reached, we established profiles of trends (described below) in these learners's responses to our survey questionnaires.

After deriving these four sets of factors, we entered them all into a Stepwise Regression Analysis, using a composite score of the differences in pre-term and post-term written compositions as a criterion variable. The only factor to explain significant amounts of variance in the criterion variable was Preferences for teacher-directed feedback, which accounted for only $8 \%$ of the variance $\left(\mathrm{R}^{2}=.08\right)$. Given this weak result, indicating our overall model was not useful for explanatory purposes, we decided to examine correlations between the outcome variables (the ratings of 5 traits of compositions) and the sets of factors for process variables among subgroups of learners, seeking to identify in a purely exploratory way any variable patterns of achievement among distinctive subgroups.

Prior ESL Instruction. This factor analysis produced a five-factor solution with high Alpha reliabilities for the 13 variables that students ticked off to describe the approaches to ESL writing instruction they had received in their home countries prior to coming to Canada. One cluster of responses grouped into a factor we call Text-oriented instruction $($ Alpha $=.52, n=98)$ including variables of reading and memorizing model texts, studying rhetorical organization, and 
writing multiple drafts of essays. A second factor we call Language-oriented instruction (Alpha $=.72, n=99)$ emerged, involving studying grammar, vocabulary, and punctuation. A third factor we call Dialogue journal instruction (Alpha $=.67, n=99$ ) included keeping diaries and meeting individually with teachers. A fourth factor we call Peer-oriented instruction (Alpha $=$ $45, n=99)$ included discussing ideas in class prior to writing as well as peer correction. The fifth factor, which we call Translation-recitation instruction (Alpha $=.43, n=99$ ), included translating model English texts into students' mother tongues, reading one's own essays aloud in class, and meeting individually with teachers.

Current Practices in ESL Writing Classes. A four-factor solution with high Alpha reliabilities emerged for students' responses to the same 13 items but in reference to the ESL writing classes in which they were presently participating. A first factor we call Input-oriented instruction (Alpha $=.58, n=99)$ included variables of reading model texts in English as well as studying grammar and vocabulary. A second factor we call Composing-processes instruction (Alpha $=.69, n=99)$ included variables of keeping diaries, studying rhetorical organization, discussing ideas in class prior to writing, writing multiple drafts of essays, peer correction, teacher conferences, and reading essays in class. A third factor we call Text-oriented instruction (Alpha $=.58, n=99)$ included variables of studying rhetorical organization and punctuation. The fourth factor corresponded to the factor of Translation-recitation instruction (Alpha $=.50, n=$ 99) identified previously in the analysis of students' prior instruction in ESL writing, including variables of translating texts into English and reading one's own essays in class, which may be an individual strategy carrying over from practices developed in students' previous ESL instruction. 
Preferences for Feedback on Writing. Items from the survey on preferences for feedback grouped neatly into a two-factor solution, distinguishing preferences for Teacher-directed feedback from preferences for Self-directed feedback on compositions. Variables clustering under the factor of preferences for Teacher-directed feedback (Alpha $=5.2, n=97$ ) were high ratings on the usefulness of teacher correction and for teacher-student conferences. Variables clustering under the factor of preferences for Self-directed feedback (Alpha $=.55, n=95)$ were high ratings on the usefulness of teacher commentary and error identification on compositions (rather than error correction), peer correction, and self-correction.

Uses of Instructional Feedback. Students' accounts of their ongoing uses of instructional feedback grouped neatly into a two-factor solution with high reliabilities for six of the eight variables on which students rated the frequency of their behaviours. One Factor we call Revising Strategies (Alpha $=.80, n=87)$ consisted of rewriting compositions, making corrections as well as expansions of ideas. The second Factor we call Studial Strategies (Alpha $=.56, n=95$ ) consisted of self-directed study strategies like making mental notes, writing down points, identifying points to be explained, and consulting dictionaries. However, two strategies--asking teachers for explanations and referring back to previous compositions--did not load onto either of these factors.

In correlating these four sets of factors with the students' achievement ratings only three notable relations appeared, again suggesting that the process variables we had selected were limited in their explanatory power. One notable trend was a negative correlation $(r=-.25, p=$ $.05, n=67$ ) between students' achievement in the communicative quality of their compositions and Input-oriented learning practices in their current ESL classes, suggesting that those students 
who focused on just comprehending English in their learning tended not to improve the communicative aspects of their writing. This finding may have important implications for Swain's Comprehensible Output Hypothesis. A second negative correlation $(r=-.29, p=.05, n$ $=67$ ) associated lack of achievement in argumentation with students who said they had used Translation-recitation practices in their ESL learning. A positive correlation $(r=.25, p=.05, n$ =69) associated students' achievement in linguistic accuracy in their writing with the factor of Preferences for teacher-directed feedback, supporting the results from the regression analyses, and suggesting that students eager to receive teacher corrections tended to improve linguistic aspects of their writing.

To further explore these data, we selected those students showing distinct achievement (1 or more points improvement between pre-post term compositions) on each of the five rating scales, then correlated their scores against the factors. Again, very few significant correlations appeared, though possibly because this analysis only accounted for a small number of students. A positive correlation $(r=.38, p=.05, n=27)$ appeared between those achievers who reported a Translation-recitation background to ESL instruction in their native countries and their achievement in argumentation in their writing. Similarly, achievement in argumentation in writing correlated negatively $(r=-.44, p=.05, n=20)$ with these achievers who reported using Studial strategies to deal with feedback on their writing.

We conducted similar correlations for the sub-group of students with relatively low proficiency in ESL writing ( 1 or more points below the mean on each of 5 rating scales). Six correlations reached statistical significance; Each points toward an aspect of ESL writing where specific learning or instructional factors may help or hinder people who have not yet attained 
threshold levels of language proficiency. Students with relatively low ESL proficiency who had previous backgrounds in Text-oriented instruction in their native countries tended not to improve their argumentation $(r=-.34, p=.05, n=33)$ or organization $(r=-.40, p=.05, n=40)$.

However, such students who reported presently using Composing process orientations to their writing showed positive correlations $(r=.25, p=.05, n=36)$ with their achievement in the communicative quality of their writing as well as positive correlations $(r=.33, p=.05, n=38)$ with their achievement in linguistic appropriacy. In terms of their reported uses of instructional feedback, students' achievement on linguistic accuracy and linguistic appropriacy correlated negatively $(r=-.37, p=.05, n=37 ; r=-.36, p=.05, n=34$, respectively) with their uses of Studial strategies.

We conducted further correlations for the sub-group of students with relatively high proficiency in ESL writing ( 1 or more points above the mean on each of 5 rating scales). The only significant relations that appeared were that achievement in these students' rhetorical organization correlated negatively with instructional backgrounds in their native countries involving Text-orientations $(r=-.40, p=.05, n=40)$ as well as Translation-recitation $(r=-.40$, $p=.05, n=40)$.

\section{Concluding Remarks: Whither Models?}

Overall, the analyses presented here failed to produce an adequate explanatory model of the relations between adult ESL students' backgrounds, processes of learning and using classroom instruction, and their achievement in ESL writing. Perhaps this aim was overly ambitious or maybe even not feasible in the absence of an explicit, prior theoretical formulation of learning to write in a second language, given the relatively small number of students assessed 
and their very diverse cultural, linguistic and educational backgrounds, and in view of the exceedingly complex set of relations we considered. But these constraints are the naturallyoccurring ones typical of adult ESL writing instruction.

Nonetheless, our analyses did make a preliminary, unique step forward in attempting to construct a process-product model of second-language writing instruction; if nothing else, we have documented some of the complexities in trying to do so, thereby providing guidance for future research. Looking to the three major issues we identified in the middle of this paper, we can claim that our research seemed successful in selecting appropriate indicators of writing achievement in a second language (with the incidental implication of providing longitudinal validation for Hamp-Lyons and Henning's rating scales), but we are uncertain that we have made more than preliminary progress in identifying the principal variables that influence learning to write in a second language or in clarifying how such variables interrelate to produce students' achievement in second-language writing.

Nonetheless, several implications from this study point toward considerations for future research and for conceptualizations of learning and teaching second-language writing. Certain implications emerge from our exploratory factor analyses and follow-up correlations with students' achievement. These analyses suggest there are particular, identifiable clusters of current practices, past experiences, or personal preferences that ESL students demonstrate in respect to second-language writing. Rather than being a simple phenomena (e.g., deriving just from norms of discourse in students' mother tongues, as described by contrastive rhetoric), there appear to be complex configurations of background and process variables that interrelate students' previous educational experiences and present practices learning to write in a second 
language (as suggested by Mohan \& Lo, 1985).

An implication is that the teaching of second-language writing needs to be conceptualized in a more sophisticated manner than the simple labels that currently predominate. For instance, what might be conventionally labelled as traditional "product-oriented" teaching turned out, in the present research, to involve three empirically different orientations to instruction, focussing either on orientations to texts, language issues, or translation-recitation practices. Likewise, what might conventionally be labelled as "process-oriented" instruction turned out, for the present students, to consist in learning behaviors oriented either toward peer interactions or those associated with dialogue-journal writing. Neither of these configurations could have been predicted readily from existing descriptions of how second-languages are taught or learned.

A further implication is that we should expect differential achievement, or aptitude by treatment effects, among (a) second-language learners with different profiles in their previous education and (b) second-language learners with different orientations to learning to write in a second language in respect to (c) different aspects of second-language written compositions. Although we would hesitate to formulate any of the findings from this study firmly as hypotheses, our findings for sub-groups of learners indicate a variety of pedagogically-relevant trends to evaluate in future studies.

Similarly, our analyses of students' preferences for and uses of feedback on their writing showed the present population dividing distinctly into several sub-types in their attitudes and behaviors, suggesting there may not be anything like a universally preferable approach for second-language writing instructors to comment on or mark students' writing. Some students prefered self-directed approaches to feedback on their writing, whereas other students prefered 
teacher-directed feedback (and results of regression analyses suggested the latter group benefited more from their teachers' feedback than the self-directed learners did). Some students revised their writing after receiving teachers' feedback, whereas others simply made mental notes of points to study later. Further research into the effects of teachers' feedback on second-language writing will need to account for these differences among students to discern what effects various approaches to feedback actually have, just as practicing teachers might sensibly adjust their feedback to accomodate second-language students' preferred learning styles and actual uses of such feedback (cf. Cohen \& Cavalcanti, 1990).

Finally, distinct evidence emerged to show the positive effects of mother-tongue writing skill on achievement in second-language writing, particularly traits of linguistic accuracy and appropriateness. This finding indicates, as proposed by Cumming (1990b) and Swain (1995), that writing expertise in learners' mother tongues may transpose into behaviors that benefit their second-language acquisition. In particular, skilled adult writers in their mother tongue were significantly better able to improve, over six weeks of instruction, linguistic aspects of their second-language writing than were adults with less writing skill in their mother tongues. 


\section{References}

Bardovi-Harlig, K. \& Bofman, T. (1989). Attainment of syntactic and morphological accuracy by advanced language learners. Studies in Second Language Acquisition, 11, 17-34.

Carroll, J. (1975). The teaching of French as a foreign language in eight countries. New York: John Wiley \& Sons.

Chaudron, C. (1988). Second language classrooms: Research on teaching and learning. New York: Cambridge University Press.

Cohen, A. \& Cavalcanti, M. (1990). Feedback on compositions: Teacher and student verbal reports. In B. Kroll (Ed.), Second language writing: Research insights for the classroom (pp. 155-177). New York: Cambridge University Press.

Cronbach, L. (1975). Beyond the two disciplines of scientific psychology. American Psychologist, 30, 116-127.

Cumming, A. (1989). Writing expertise and second language proficiency. Language Learning, $39,81-141$.

Cumming, A. (1990a). Expertise in evaluating second-language compositions. Language Testing, 7, 31-51.

Cumming, A. (1990b). Metalinguistic and ideational thinking in second-language composing. Written Communication, 7, 482-511.

Cumming, A. (1992). Instructional routines in ESL composition teaching. Journal of Second Language Writing, 1, 17-35.

Cumming, A. (1994). Recent trends in research on biliteracy. In A. Cumming (Ed.), Bilingual performance in reading and writing (pp. 1-20). Amsterdam: John Benjamins. 
Cumming, A. (In press). The testing of writing in second languages. To appear in C. Clapham (Ed.), Language testing and assessment. Vol 7 of D. Corson (Ed.) The encyclopedia of language and education. Dordrecht, Netherlands: Kluwer.

Cumming, A. \& Gill, J. (1991). Learning ESL literacy among Indo-Canadian women. Language, Culture and Curriculum, 4, 181-200.

Cumming, A. \& Mellow, D. (1996). An investigation into the validity of written indicators of second language proficiency. In A. Cumming \& R. Berwick (Eds.). Validity in language testing (pp. 72-93). Clevedon, Avon: Multilingual Matters.

Cummins, J. (1991). Interdependence of first and second language proficiency in bilingual children. In E. Bialystok (Ed.) Language processing in bilingual children (pp. 70-89). Cambridge: Cambridge University Press.

Ellis, R. (1994). The study of second language acquisition. Oxford: Oxford University Press. Gage, N. \& Needels, M. (1989). Process-product research on teaching: A review of criticisms. Elementary School Journal, 89, 253-300.

Hamp-Lyons, L. (1991). Reconstructing "academic writing proficiency" In L. Hamp-Lyons (Ed.), Assessing second language writing in academic contexts (pp. 127-153). Norwood, NJ: Ablex.

Hamp-Lyons, L. \& Henning, G. (1991). Communicative writing profiles: An investigation of the transferability of a multiple-trait scoring instrument across ESL writing assessment contexts. Language Learning, 41, 337-373.

Harley, B., Allen, P, Cummins, J. \& Swain, M. (Eds.) (1990). The development of second language proficiency. New York: Cambridge University Press. 
Hirose, K. \& Sasaki, M. (1994). Explanatory variables for Japanese students' expository writing in English: An exploratory study. Journal of Second Language Writing, 3, 203-229.

Hornberger, N. (1989). Continua of biliteracy. Review of Educational Research, 59, 271-296.

Jacobs, H., Zinkgraf, S., Wormuth, D., Hartfiel, V. \& Hughey, J. (1981). Testing ESL composition: A practical approach. Rowley, MA: Newbury House.

Kern, R. \& Schultz, J. (1992). The effects of composition instruction on intermediate level French students' writing performance: Some preliminary findings. Modern Language Journal, 76, 1-13.

Mohan, B. \& Lo, W. (1985). Academic writing and Chinese students: Transfer and developmental factors. TESOL Quarterly, 19, 515-534.

Purves, A. (1992). Reflections on research and assessment in written composition. Research in the Teaching of English, 26, 108-122.

Raimes, A. (1990). The TOEFL Test of Written English: Causes for concern. TESOL Quarterly, $24,427-42$.

Raimes, A. (1991). Out of the woods: Emerging traditions in the teaching of writing. TESOL Quarterly, 25, 407-430.

Riazi, A., Lessard-Clouston, M. \& Cumming, A. (1994, October). The nature of classroom ESL writing instruction. Paper presented at the Second Language Research Forum, Montreal.

Saito, H. (1994). Teachers' practices and students' preferences for feedback on second language writing. TESL Canada Journal, 11, 46-70.

Sasaki, M. \& Hirose, K. (1996). Explanatory variables for EFL students' expository writing. Language Learning, 46, 137-174. 
Shi, L. \& Cumming, A. (1995). Teachers' conceptions of second-language writing instruction: Five case studies. Journal of Second Language Writing, 5, 87-111.

Silva, T. (1990). Second language composition instruction: Developments, issues, and directions in ESL. In B. Kroll (Ed.), Second language writing: Research insights for the classroom (pp. 11-23). New York: Cambridge University Press.

Silva, T. (1993). Toward an understanding of the distinct nature of L2 writing: The ESL research and its implications. TESOL Quarterly, 27, 657-677.

Stern, H. (1983). Fundamental concepts of language teaching. Oxford: Oxford University Press.

Swain, M. (1995). Three functions of output in second language learning. In G. Cook \& B. Seidelhofer (Eds.) Principle and practice in applied linguistics (pp. 125-144). Oxford: Oxford University Press.

Tarone, E., Downing, B., Cohen, A., Gillette, S., Murie, R. \& Dailey, B. (1993). The writing of Southeast Asian-American students in secondary school and university. Journal of Second Language Writing, 2, 149-172.

Valdez, G., Haro, P. \& Echevarriarza, M. (1992). The development of writing abilities in a foreign language: Contributions toward a general theory of L2 writing. Modern Language Journal, 76, 333-352.

Whalen, K. \& Menard, N. (1995). L1 and L2 writers' strategic and linguistic knowledge: A model of multiple-level discourse processing. Language Learning, 45, 381-418.

Zamel, V. (1995). Strangers in academia: The experiences of faculty and ESL students across the curriculum. College Composition and Communication, 46, 506-521. 